\title{
A regionalização do turismo no Estado do Paraná sob a perspectiva do marketing
}

The regionalization of tourism in the State of Paraná from a marketing perspective

Francisco José Gouveia de Castro - Mestre em Turismo, Universidade Federal do Paraná (UFPR), Curitiba - Brasil - fjgcastro@gmail.com

José Manoel Gonçalves Gândara - Doutor em Turismo e Desenvolvimento Sustentável, Universidad de Las Palmas de Gran Canaria, Las Palmas - Espanha -

jmggandara@yahoo.com.br

\section{RESUMO}

A literatura do turismo realizado de forma experiencial influenciou a elaboração do plano de marketing turístico no Estado do Paraná devido à importância que o tema tem alcançado nas últimas três décadas e, como resultado disso, a categorização e identificação dos perfis de consumo que demandam por atrativos que são ofertados no território paranaense. A questão que se coloca é: como se configuram as regiões turísticas no Paraná de acordo com a oferta de atrativos para buscadores de experiência? O presente trabalho tem o objetivo de identificar e analisar as regiões turísticas de acordo com a localização dos principais atrativos turísticos ofertados para os diversos perfis de experiências. Para alcançar este objetivo utilizou-se a técnica de pesquisa de levantamento descritiva. O estudo tem caráter exploratório-descritivo com forte viés qualitativo, como descrição dos resultados obtidos a partir do embasamento teórico proveniente da literatura acerca da economia da experiência e do marketing de destinos turísticos. Em relação à territorialização, utilizou-se conceitos de espaço turístico ancorados nas ideias de Douglas Pearce (2015) e Barrado-Timon (2004) entre outros. Como resultado do estudo, conclui-se que os esforços da governança do turismo, as peculiaridades históricas e demográficas na formação dos principais atrativos permitiram a formação de um ambiente favorável à satisfação das necessidades dos turistas. Observou-se que as ofertas de destinos turísticos se caracterizam pela concentração territorial em torno dos grandes centros urbanos, pela dinâmica demográfica dos municípios que as compõem, o que é favorecido devido à infraestrutura e pelo contingente demográfico, que gera a demanda por esses produtos. Palavras-chave: Regionalização, Marketing, Experiência, Turismo, Paraná. 


\section{ABSTRACT}

The experiential tourism literature has influenced the elaboration of the tourism marketing plan in the State of Paraná due to the importance that the theme has reached in the last three decades and, as a result, the categorization and identification of consumption profiles that demand attractive that are offered in Paraná. The question that arises is: how are the tourist regions in Paraná configured according to the offer of attractions for experience seekers? This paper aims to identify and analyse the tourist according to the location of the main tourist attractions offered for the various experience profiles. To achieve this objective goal the descriptive survey research technique was used. The study has an exploratory-descriptive character with strong qualitative bias, as a description of the results obtained from the theoretical background from the literature on the economics of experience and marketing of tourist destinations. Regarding territorialisation, concepts of tourism space anchored in the ideas of Douglas Pearce (2015) and Barrado-Timón (2004) among others were used. As a result of the study, it is concluded that the efforts of tourism governance, the historical and demographic peculiarities in the formation of the main attractions allowed the formation of an favourable environment to the satisfaction of tourists needs. It was observed that the offer os tourist destinations is characterized by the territorial concentration around the large urban centres, the demographic dynamics of the municipalities that compose them, which is favoured due to the infrastructure and the demographic contingent, which generates the demand for these products.

Keywords: Regionalization, Marketing, Experience, Tourism, Paraná.

\section{INTRODUÇÃO}

O ponto de partida para o embasamento teórico do presente trabalho são os conceitos acerca da economia da experiência e do Marketing do Destino Turístico. Tais temas nortearam, por conseguinte, a formulação do Plano Paraná Turístico 2026 - Pacto para um Destino Inteligente (2016), e o Plano de Marketing Estratégico do Estado do Paraná 2016 - 2026, os quais utilizaram-se da técnica de pesquisa da Netnografia para identificar os destinos/atrativos mais adequados aos perfis de consumo dos buscadores de experiências turísticas apresentados nos referidos Planos. 
Aliás, tais planos foram inspirados nas dimensões de experiências fundamentadas nos trabalhos de Pine e Gilmore (1999), expostos e analisados por diversos outros autores ao longo do tempo. Conforme Mehmetoglu e Engen (2015), essa percepção, de modo geral, parte dos conceitos fundamentais da literatura de Marketing de Destino Turístico, que é a formação da tipologia de demanda turística por destinos para turismo de experiência.

Diante desse arcabouço teórico instrumental proposto por Pine e Gilmore, o estudo de Amadeus (2015) traçou os perfis de buscadores de experiências turísticas, projetando o que foi chamado de tribos para 2030, os quais se seguem descritos a seguir.

Os buscadores de simplicidade, se caracterizam por valorizarem, acima de tudo, mais facilidades e transparências no seu planejamento de viagens e férias, estando dispostos a terceirizar sua tomada de decisão para partes confiáveis. Esse grupo é composto praticamente por idosos (Amadeus, 2015).

Já o segundo grupo, que são os puristas culturais, tratam suas viagens como uma oportunidade de mudar completamente sua vida no dia a dia e envolvem-se com uma maneira diferente de viver. Esta tribo é semelhante aos viajantes cosmopolitas (Amadeus, 2015).

A terceira tribo, segundo a classificação de Amadeus (2015), os requerentes de capital social, entendem que ser muito viajado é uma qualidade pessoal e suas escolhas são moldadas ao desejo de levar a máxima recompensa social de suas viagens. Eles vão explorar o potencial das mídias digitais para enriquecer e informar suas experiências e estruturar suas aventuras.

A quarta tribo foi denominada por Amadeus (2015) como Caçadores de Recompensa, que são os viajantes de luxo do futuro e que buscam um retorno sobre o investimento que fazem em suas vidas de realizações. Este perfil está ligado, em parte, à crescente tendência de bem-estar físico e mental e o auto aperfeiçoamento. 
Os buscadores de obrigações, quinta tribo proposta por Amadeus (2015), tem suas escolhas de viagens limitadas pela necessidade de encontrar algum objetivo limitado. Embora procurem organizar e improvisar outras atividades, o núcleo e o comportamento da viagem devem estar em determinado local e em determinado momento.

Por último, os viajantes éticos são guiados por sua consciência na realização das viagens. Deixam os ideais políticos e ambientais moldarem suas escolhas. Esses viajantes têm maior consciência das maneiras de como gastar em seu destino turístico (Amadeus, 2015).

Diante da elaboração do estudo de Amadeus e da tipologia construída por Pine e Gilmore (1999), a justificativa para a utilização de perfis de buscadores das experiências turísticas se dá pela mudança da dinâmica, não só demográfica, mas a importância da abordagem psicológica e traços de personalidades.

Quanto aos procedimentos metodológicos, o trabalho é caracterizado pelo caráter exploratório e descritivo com viés qualitativo. De fato, foi considerado o número de avaliações do TripAdvisor no sentido de identificar os principais destinos turísticos do estado, bem como os atrativos ali encontrados. A partir deste levantamento e sistematização, foi possível a hierarquização dos municípios, por conseguinte, a definição de regiões turísticas do Estado desde uma perspectiva de marketing.

Dessa forma, este estudo propõe a seguinte problemática de pesquisa: no Estado do Paraná, como se configuram as regiões de turismo segundo a oferta de atrativos para os diversos perfis de buscadores de experiências, segundo a perspectiva do marketing?

A título de conclusão, diante da problemática proposta neste trabalho, observou-se que as ofertas de destinos turísticos se caracterizam pela concentração territorial, pela homogeneidade e pela dinâmica demográfica dos municípios que as compõem. 
A partir deste estudo, é possível propor um aprofundamento das técnicas administrativas e políticas numa perspectiva interdisciplinar e integrada para o desenvolvimento turísticos das regiões identificadas.

\section{FUNDAMENTOS TEÓRICOS DO MARKETING DE DESTINOS TURÍSTICOS NO ÂMBITO DAS DIMENSÕES DE EXPERIÊNCIAS}

Na concepção da moderna ideia de Planejamento, a sintonia fina entre o setor público, a iniciativa privada, a sociedade civil organizada e a academia são fundamentais para o sucesso do desenvolvimento regional. Nesse sentido cabe citar Buhalis (2000), que apresentou uma explanação coerente quando se trata da participação dos agentes públicos, no qual o marketing de destino facilita a consecução da política de turismo, que deve ser coordenada junto com o plano estratégico de desenvolvimento. A comercialização do destino também deve orientar a otimização dos impactos turísticos e a maximização dos benefícios para a região.

Diante desta perspectiva, cabe destacar o conceito de Organização de Gerenciamento de Destino (DMO, sigla em inglês), que deve ser compatível com o planejamento e comercialização da região e tenha o poder e os recursos necessários para realizar ações para alcançar objetivos estratégicos (Buhalis, 2000).

De fato, observa-se que esse é o princípio inicial dos planos de marketing e de desenvolvimento voltado para o tema, que pressupõe um processo de construção conjunto pactuado entre o poder público, a iniciativa privada, a sociedade civil, e regiões turísticas.

Além disso, as DMOs tendem a "fazer parte do governo local, regional ou nacional e têm políticas e poder legislativo, bem como os meios financeiros para gerenciar recursos de forma racional e garantir que todas as partes interessadas possam se beneficiar a longo prazo" (Buhalis, 2000, p. 3). 
Dessa forma, "a gestão de destinos e o marketing devem atuar como ferramentas e facilitadores para alcançar uma gama complexa de objetivos estratégicos" (Buhalis,2000, p. 3)

O marketing do turismo não só deve ser considerado como uma ferramenta para atrair visitantes para uma região, mas deve funcionar como "um mecanismo facilitador para alcançar os objetivos de desenvolvimento regional e racionalizar a provisão de turismo para garantir que os objetivos estratégicos dos destinos sejam alcançados" (Buhalis, 2000, p. 3). Tal referencial parece nortear, como um conjunto, a elaboração do plano de marketing do turismo paranaense.

A contribuição de Barrado-Timón (2004) foi importante para traçar as diretrizes em relação aos aspectos territoriais, pois "com o processo de produção-consumo turístico, se gera uma nova realidade socioespacial diferenciada que é o destino e que participa, ao mesmo tempo, dos aspectos setoriais e geográficos" (p. 55). Portanto, para o autor, o destino deve ser entendido como "subsistema formado por elementos espaciais, administrativos e produtivos; assim como pelo conjunto de suas interrelações e os efeitos que produzem, que são fundamentalmente setoriais e geográficos" (Barrado-Timón, 2004, p. 56).

Com essa abordagem, é possível traçar a disposição das informações que contemplam os planos de marketing turísticos. Contudo, a partir desse recorte territorial e setorial, é premente a necessidade da concepção da governança da gestão do destino turístico e do produto a ser ofertado.

Nesse sentido, "é necessário que haja interação entre todas as partes interessadas do sistema turístico na formação de redes de cooperação público-privadas para a entrega de uma experiência de sucesso ao turista" (Flores \& Mendes, 2014, p. 233). Para os autores, "as organizações de gestão do destino têm sua função ampliada para a integração dos esforços e gestão dos recursos" (p. 233). 
Ainda em relação aos conceitos territoriais, Pearce (2015) desenvolve uma concepção integrada de destinos identificando e sintetizando os elementos-chave de cinco grandes conjuntos de conceitos: distritos industriais, clusters, redes, sistemas e construções sociais.

Seguindo a mesma concepção geográfica de Pearce (2016), Jovicic (2016) analisa o conceito de destino turístico partindo da abordagem clássica/tradicional passando pela abordagem sistêmica e terminando com o destino turístico inteligente e enfatizando as mudanças recentes, com o avanço das Tecnologias de Comunicação e Informação.

Já na abordagem do comportamento do consumidor, Cohen, Prayag e Moital (2016) avaliam as influências externas sendo identificadas como importantes fatores contemporâneos sobre o turismo, os quais, tecnologia, geração e o aumento da preocupação ética nas decisões do consumidor. Para os autores, os consumidores "usam tecnologia para muitas tarefas relacionadas ao consumo, como busca de informações, comprando, compartilhando opiniões e experiências e entretenimento" (Cohen, Prayag \&Moital, 2016).

Cohen, Prayag e Moital (2016) destacam a influência da tecnologia na formação do comportamento do consumidor do turismo, o que faz com que os pesquisadores dediquem mais atenção a esta área que se caracteriza pelas rápidas mudanças.

Com essa perspectiva do comportamento do consumidor e as influências externas, o plano estratégico de marketing dos destinos turísticos deve estabelecer as tendências-chaves, como "influência estratégica da definição dos perfis dos consumidores" e "predominância do uso das tecnologias de informação e comunicação" (Cohen, Prayag \& Moital, 2016).

Na economia da experiência, o turista assume um papel importante na cadeia de produção, ou seja, "a realização de um projeto de consumo, reunindo recursos em um conjunto de consumo que é necessário para produzir uma experiência de turismo. Os bens e serviços de turismo são 
produzidos para produzir experiências" (Andersson, 2007, p. 47). Nesse caso, segundo o autor, "O turista assume a responsabilidade pela "produção final" que determinará o valor final de toda a cadeia de produção". "O resultado desse processo, onde o turista é ativo, é determinado por habilidades, criatividade e conhecimento, bem como o tempo e outros recursos do turista".

A mesma abordagem é encontrada no estudo de Richards (2014), que introduz a ideia de "reprodução do cotidiano", o que envolve trabalho emocional por parte de guias de turismo e outros atores envolvidos na produção de espaços. A incorporação das experiências - vida no dia a dia em locais visitados é uma das motivações de viagem mais importantes para os novos turistas culturais ou criativos (Richards, 2014).

Nessa perspectiva, o que justifica também o planejamento de roteiro de produtos turísticos são "as práticas emergentes, que são o resultado da combinação de recursos, habilidades e significados. O novo sistema de cocriação de espaço entre turistas e residentes têm sido um resultado importante das mudanças nas práticas de turismo" (Richards, 2014, p. 9).

Saraniemi e Kylänen (2014) introduzem a abordagem holística e o trabalho de imagem e implementação de táticas administrativas unilaterais para uma análise sociocultural de longo prazo. O objetivo desta abordagem é "construir uma área de marca de destino, construindo geografias locais ou promovendo cooperação entre as diferentes partes interessadas na mesma região" (Saraniemi \& Kylänen, 2014, p. 133).

No presente artigo, é fundamental o uso da tipologia das dimensões de experiências, elaboradas por Pine e Gilmore (1998), que foram categorizadas em absorção, imersão, participação ativa e passiva. No modelo estrutural, as variáveis utilizadas para explicar e caracterizar o perfil da demanda foram a educação, escapismo, estética e entretenimento. Esse modelo serve de ponto de partida ao planejamento e para a oferta segmentada de produtos 
turísticos com a inclusão de itens como definição estratégica de segmentos e produtos.

Essa estratégia também é referenciada por Prebensen e Foss (2011), que seguindo a abordagem de co-criação no turismo de experiência e propuseram uma estrutura com duas vertentes para as estratégias de lidar com o turista: a cognitiva e a comportamental. Os autores narram como os viajantes lidam com várias pessoas e situações em termos de elementos cognitivos e comportamentais no sentido de regular as emoções nas diversas experiências.

Ou seja, pressupõe que o turista está lidando com as emoções e reações controlando o escapismo, uma vez que se orienta para a aprendizagem e evitam situações e pessoas chatas (Prebensen e Foss, 2011).

Já Binkhorst (2008), destaca o trabalho em rede numa abordagem da economia da experiência. Tal rede abarca uma série de atores integrados e utiliza-se do aparato tecnológico disponível. Tal processo tem como fim a agregação de valor, uma vez que o turismo "representa um gerador de experiências e um motor econômico de primeira ordem" (Binkhorst, 2008, p. 49).

Na mesma abordagem, vale ressaltar as contribuições de Neuhofer, Buhalis e Ladkin (2012), que reconhecem o impacto da tecnologia nas experiências e a conceptualização holística na ausência de mudança. Os autores destacam o papel das Agências Gerenciadoras de Destinos nesse novo paradigma tecnológico, mais especificamente na necessidade de achar diferentes significados para atração do consumidor.

A melhoria tecnológica para a gestão de experiências nos destinos foi esquematizada a partir da intersecção de diversos fatores que compõem a co-criação: oferta turística, demanda turística, co-consumo turístico e redes sociais. Contudo, tais pilares estão alicerçados nas tecnologias de comunicação e informação (Neuhofer, Buhalis \& Ladkin, 2012). 
Diante desse aparato referencial, se destaca a importância da regionalização dos destinos turísticos do Estado do Paraná, que servem como instrumento estratégico para 0 desenvolvimento dos produtos turísticos, contribuindo para a construção da imagem, identidade e posicionamento junto ao mercado consumidor. Para tal, a utilização das Tecnologias de Comunicação e Informação (TIC), é o instrumento que determinará o sucesso da divulgação, implementação, monitoramento, avaliação e resultado do Planejamento Estratégico dos Destinos Turísticos.

As desigualdades territoriais têm gerado inúmeros estudos que começaram a estimar e valorar os problemas inerentes ao espaço geográfico. São diferenças que se expressam geograficamente nas disparidades entre regiões e também dos municípios que as compõem. Tais diferenças são resultados históricos da formação e desenvolvimento de determinada localidade, que resulta dos principais componentes estruturais, influenciando na formação de diferentes perfis tipológicos de população, estrutura de serviços, infraestrutura de transporte, condições naturais e culturais, entre outros.

\section{PROCEDIMENTOS METODOLOGICOS}

Para alcançar o objetivo traçado neste trabalho, bem como responder as questões de pesquisa apresentadas, é premente a definição do procedimento metodológico a ser adotado para chegar a um resultado satisfatório e conclusivo.

No presente trabalho, o pressuposto filosófico adotado na concepção ontológica é o objetivismo, uma vez que o conhecimento da verdade deve representar a realidade independentemente da perspectiva a partir da qual ela é vista. A estratégia para superar os limites dos pontos de vista pessoal e cultural é estabelecer um método de investigação que garanta que todos os que o seguem tenham a mesma visão verdadeira (Polkinghorne, 1989 como citado em AYIKORU, 1989). 
No que tange à epistemologia ou a natureza do conhecimento, adotou-se uma abordagem positivista, uma vez que o enfoque é a análise empírica, envolvendo a coleta e análise de dados para a conformação de um conjunto de variáveis que representam a população localizada em recortes territoriais com características homogêneas e, ao mesmo tempo, heterogêneas entre si.

Este trabalho tem o caráter exploratório-descritivo, com forte viés qualitativo como descrição dos resultados obtidos a partir do embasamento teórico proveniente da literatura acerca do marketing de destinos turísticos, seguindo a abordagem das dimensões de experiências de Pine e Gilmore (1998).

É exploratório porque busca explorar o que está acontecendo e fazer perguntas a respeito e ao mesmo tempo descritivos porque tem a finalidade de proporcionar um quadro de fenômeno como ele ocorre naturalmente (Gray, 2012).

De fato, as pesquisas de levantamento descritivas "visam avaliar as características de uma determinada população, em um determinado momento ou comparativamente ao longo do tempo, elas são voltadas a avaliar o que ocorreu, em vez de porquê" (Gray, 2012, p. 180).

Foi construída uma tipologia a partir do número de avaliações do TripAdvisor, realizadas entre janeiro e março de 2018 nos 399 municípios do Estado do Paraná, considerando aspectos como: hospedagem, alimentação e atrativos (o que fazer). O critério utilizado para a definição dos municípios relevantes turisticamente desde uma perspectiva de marketing foi que as localidades possuíssem mais de 2.000 avaliações e que os atrativos contabilizassem mais de 100 avaliações.

Com o corte de 2.000 avaliações, pressupõe-se a possibilidade de utilização da infraestrutura de alojamento e alimentação ofertada na cidade e não só os atrativos em si. Contudo, alguns municípios foram inclusos, mesmo com menos de 2.000 avaliações, devido à necessidade de 
atenção a atrativos localizados em tais localidades, que contavam com mais de 100 avaliações.

Já para consolidar as informações regionalizadas no Estado, adotou-se um critério de hierarquização segundo o número total de avaliações registradas no TripAdvisor, categorizado a partir de quanto maior o número de avaliações, maior a importância do município na hierarquia da regionalização.

A partir dessa sistematização, foram agrupados os municípios de acordo com o valor absoluto das avaliações observadas no TripAdvisor. Em um segundo momento, os municípios contíguos foram agrupados no sentido de se vislumbrar uma conformação de região turística.

Diante desse processo de regionalização, foi possível a análise dos atrativos ali localizados, seguindo os critérios estabelecidos por Pine e Gilmore (1998), adaptado por Amadeus (2015) e constantes no Plano Paraná Turístico 2026, que foram os perfis de buscadores de experiências.

\section{ANÁLISE E DISCUSSÃO DE RESULTADOS}

O referencial teórico acerca da economia da experiência, amplamente discutido e aplicado nos meios acadêmicos e nos sistemas de planejamento da iniciativa privado e do setor público, levou a adoção de uma tipologia elaborada a partir do critério proposto por Pine e Gilmore (1998) e, posteriormente, refinado com base em Amadeus (2015), quando da criação das tribos e perfis de buscadores de experiências, sendo o termo cunhado como personas.

As personas, segundo o Paraná Turístico 2026 (2016)

Foram construídas considerando os conceitos básicos da Economia da Experiência, de Pine II e Gilmore (1999) que destacam que os consumidores mais do que simples consumidores de produtos e serviços, consomem histórias e experiências. Estes conceitos foram tomados como base por se adaptarem à atividade turística e cada vez 
mais estarem sendo utilizados como parâmetros pelos principais destinos turísticos mundiais. (p. 78)

Essa abordagem foi utilizada na construção dos "Perfis da demanda turística para o Paraná em 2016", no "Plano Paraná Turístico 2026 - Pacto para um Destino Inteligente" (2016), elaborados a partir da parceria entre a iniciativa privada e o setor público. Posteriormente, por meio desses estudos, tem-se elaborado o Plano Estratégico de Marketing Turístico do Paraná 2016 -2026 (2018).

Um dos objetivos do Plano Paraná Turístico 2026 (2016) é subsidiar as estratégias de marketing e inovação "visando o desenvolvimento de destinos e produtos turísticos diferenciados e com qualidade" (Paraná Turístico 2026, 2016, p. 78), foi realizado um estudo denominado "Perfis da Demanda Turística para o Paraná Turístico 2026".

Esses perfis de demanda respondem pelos conceitos de personas, que consiste em

Uma técnica de design que tem o objetivo de projetar produtos considerando o caráter homogêneo dos seus consumidores. Por meio da elaboração de personas é possível determinar perfis de consumidores para determinados produtos ou serviço a ser desenvolvido (Horodyski, 2014, p. 26)

Na tipologia sugerida, desenhou-se 10 perfis de turistas que serão possíveis consumidores do destino turístico do Estado, divididos em 4 grupos, conforme a figura 1.

O grupo Entretenimento se caracteriza pela participação passiva, pela conexão direta com o ambiente e a utilização dos cinco sentidos, proporcionando satisfação, riso e relaxamento. O grupo aprendizagem caracteriza-se pela participação ativa, a absorção do que é ensinado em combinação com o distanciamento do ambiente. Já o grupo evasão envolve a participação ativa relacionada à imersão ao ambiente e por fim, o quarto grupo estética/contemplação permite que o indivíduo imerge no 
ambiente, com participação passiva, com a função de apreciação (Mondo \& Gândara, 2017).

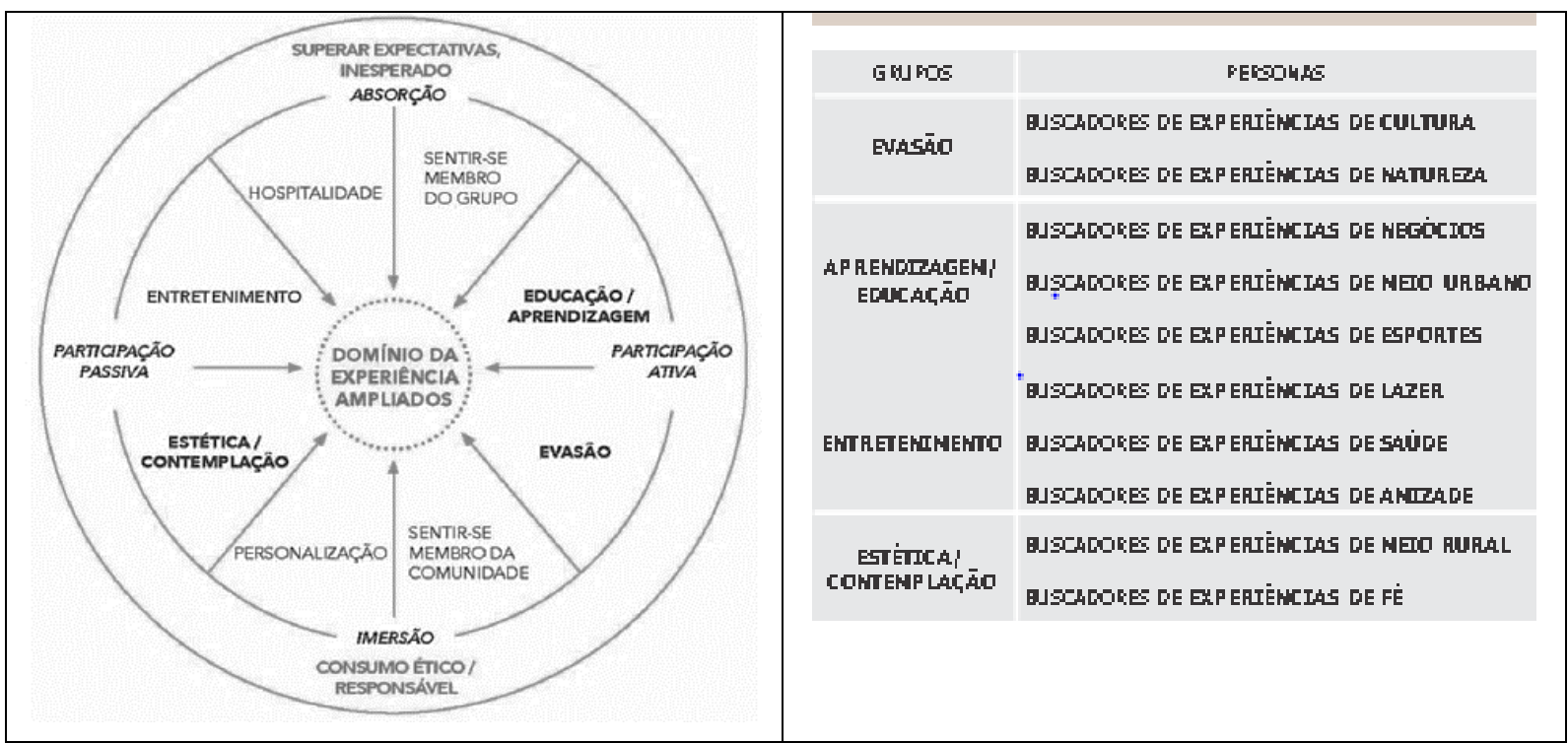

Figura 1. Domínio da experiência

Fonte: Plano Paraná Turístico 2026: Pacto para um destino inteligente (2016, p.79)

Diante da tipologia acima registrada, o Plano Paraná Turístico 2026 Pacto para um destino inteligente (2016) não traçou roteiros turísticos de ofertas para os buscadores de experiências, porém sugere que se faça isso segundo esses 10 perfis de demanda.

A tipologia de buscadores de experiência, proposta pelos estudos acima, foi construída com base nas informações, avaliações e comentários do TripAdvior, inclusive com a intensão de, posteriormente, ser elaborado um mapa de regionalização dos principais destinos identificados segundo a metodologia já comentada neste trabalho.

Ao analisar a regionalização dos principais destinos turísticos do Paraná, é possível verificar que não há uma conformidade contígua no território estadual que extrapola os grandes centros urbanos. De fato, segundo a figura 2, observa-se, no topo da hierarquia geográfica, que os municípios de Curitiba e Foz do Iguaçu no primeiro grupo, com mais de 200.000 avaliações cada um. Em seguida, na segunda faixa de agrupamento, surgem Londrina 
e Maringá. No terceiro grupo os municípios de Cascavel, Ponta Grossa e Paranaguá.

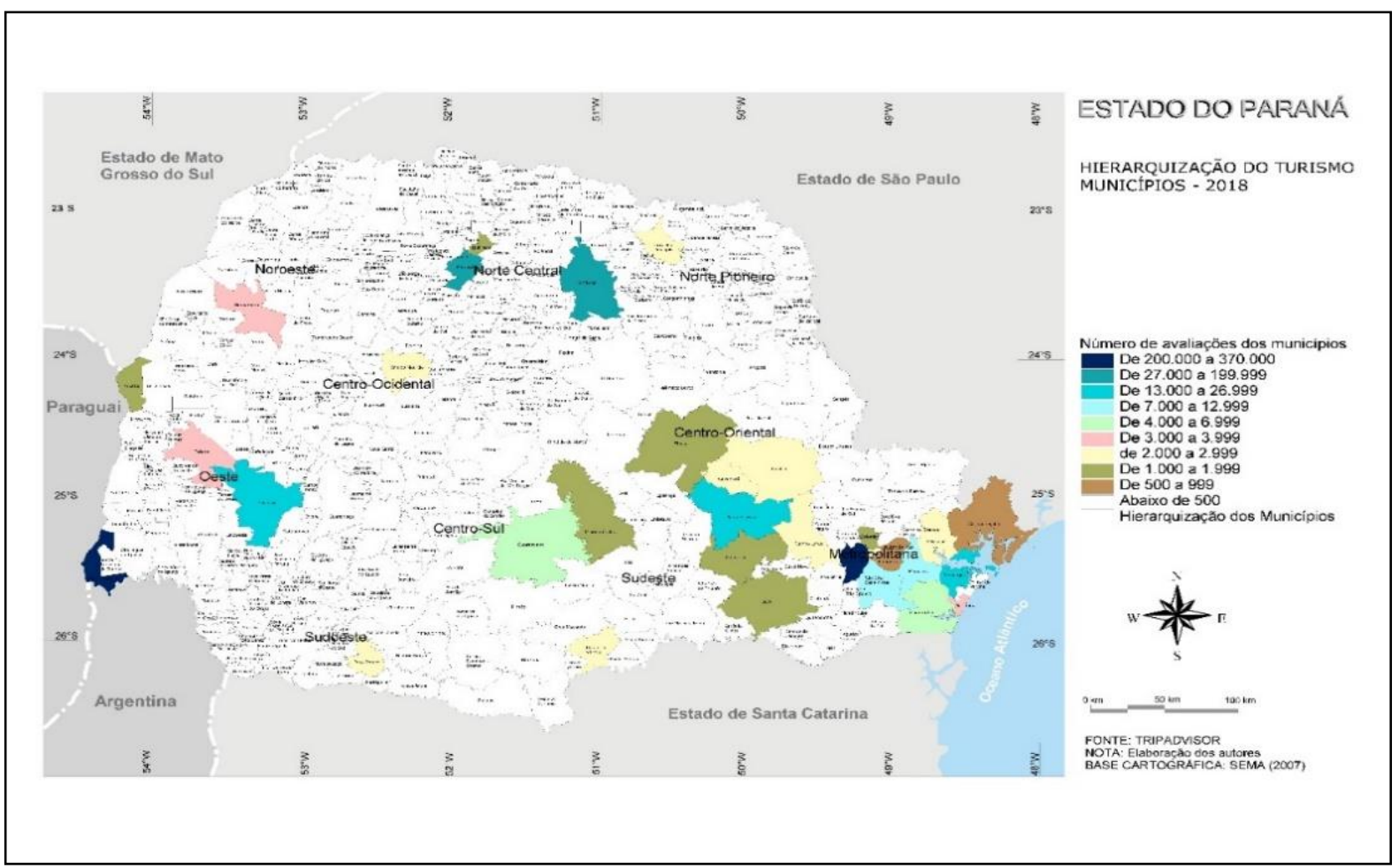

Figura 2. Hierarquização do turismo no Paraná

Fonte: Plano Estratégico de Marketing Turístico.

Diante desse critério de hierarquização, uma primeira observação dos resultados obtidos, pressupõe-se que os principais destinos turísticos do Estado do Paraná estão vinculados ao maior contingente populacional e à história de formação étnica dos municípios. Não por acaso, os grandes centros urbanos aparecem no topo da procura por atrativos turísticos no estado.

O município de Curitiba, capital do Estado e possuidor do contingente estimado em 1,9 milhão de habitantes, segundo o Instituto Brasileiro de Geografia e Estatística (IBGE), contempla os quatro grupos de demanda turística e nove dos dez perfis de buscadores, com exceção de buscadores de experiência de saúde e Meio Rural. 
Dentre os principais atrativos de Curitiba, segundo o TripAdvisor, cabe destacar, no grupo evasão, o Museu Oscar Niemeyer, o Bosque do Papa, a Estrada da Graciosa e a Serra Verde Express. Já no grupo Aprendizagem/Educação, os destaques são a Ópera de Arame, o Teatro Guaíra, o Bairro Santa Felicidade, a Feira do Largo da Ordem, a Linha Turismo e Arena da Baixada.

No que tange às experiências de Entretenimento, cabe destacar o Parque Barigui, o Bosque do Alemão, a Torre Panorâmica e várias colônias de imigrantes. Por fim, no grupo Estética/Contemplação, os destaques são: a Catedral Metropolitana Nossa Senhora da Luz dos Pinhais, a Mesquita Imam Ali Ibn Abi Talid e a Igreja Presbiteriana Independente de Curitiba.

O município de Foz do Iguaçu, localizado no extremo oeste paranaense, possui o efetivo populacional estimado em 264 mil habitantes. Neste território há atrativos que contemplam os quatro grupos de demanda e os dez perfis de buscadores de experiências. Dentre eles, segundo o TripAdvisor, os maiores destaques são, no grupo evasão: a Usina Hidrelétrica de Itaipu, o Museu de Cera Dreamland, o Marco das Três Fronteiras, as Cataratas do Iguaçu, o Parque das Aves e o Parque Nacional do Iguaçu.

No que tange ao grupo Aprendizagem/Educação, os destaques são: Iporã-Rafain Churrascaria Show, Ponte Internacional da Amizade, Rafting no Rio Iguaçu e Rapel no Cânion Iguaçu. Em relação ao grupo Entretenimento, importa citar a Helisul -Taxi Aéreo e Voos Panorâmicos, Acquamania Foz, Thermas Parque Aquático Cataratas, Belmond Hotel das Cataratas, Recanto Cataratas Thermas R. \& C. e várias colônias de imigrantes.

Por fim, em relação ao grupo Estética/Contemplação, os principais atrativos são: o Templo Budista, a Mesquita Omar Ibn Al Jhatab e a Catedral São João Batista.

No segundo grupo (de 27.000 a 199.999 avaliações), Londrina, com população estimada em 558.439 habitantes, oferta no grupo evasão: o Museu Histórico de Londrina e o Jardim Botânico de Londrina. No grupo 
Aprendizagem/Educação, os destaques são: o Parque de Exposição Governador Ney Braga e o Autódromo Internacional Ayrton Senna. Em Entretenimento cabe destacar o Lago Igapó e a Colônia de Imigrantes japoneses. Por fim, o grupo Estética/Contemplação inclui o Santuário de Graças Schoenstartt e a Catedral Metropolitana de Londrina.

No mesmo grupo hierárquico de Londrina, está o município de Maringá, com contingente populacional estimado em 406.693 habitantes, oferta atrativos como o Teatro Calil Haddad, Mercadão de Maringá, Praça de Conveniência, Estádio Regional Willie Davids, Parque do Japão, Bosque das Grevíleas, Parque Alfredo Nyffler e a Catedral Basílica Menor Nossa Senhora da Glória.

Não menos importante para essa análise, cabe destacar os municípios de Ponta Grossa e Paranaguá por suas relevâncias como centros regionais. Ponta Grossa, com o contingente de 341.130 habitantes, segundo o IBGE, é o centro regional dos campos gerais, com grande destaque na conformação de Região de Turismo do Paraná.

Os atrativos Pontagrossenses mais relevantes em termos de marketing são: o Parque Estadual de Vila Velha e o Buraco do Padre para buscadores de experiências de natureza, as colônias de imigrantes alemães para buscadores de perfis de amizade e a Catedral Sant'Ana e a Abadia da Ressureição no que se trata de experiências de fé.

No mesmo grupo, o município litorâneo de Paranaguá é um centro turístico com atrativos para buscadores de experiências de cultura, como o Museu de Arqueologia da Universidade Federal do Paraná; de natureza, como é o caso do Aquário Marinho; de meio urbano, representado pelo Mercado Municipal do Café; de amizade com a colônia de imigrantes árabes; e, o destaque da llha do Mel, com atrativos interessantes para buscadores de experiências de natureza e lazer.

Definido a hierarquização dos destinos turísticos no Estado do Paraná, seguindo os critérios já estabelecidos, passou-se a categorizar o 
ordenamento territorial a partir das Regiões Turísticas, as quais chegou-se a três grupos de aglomerações caracterizadas por perfis geográficos bem definidos: Região Turística do Litoral, Região Turística Metropolitana de Curitiba e Região Turística dos Campos Gerais (figura 3).

Já os municípios do restante do território estadual não se enquadraram em regiões turísticas por não serem contíguos, estão isolados de outros polos e serem homogêneos entre si, como foi possível identificar na figura 2.

Cabe destacar que tais municípios se caracterizam por apresentarem empreendimentos que se sustentam devido à economia de escala, ou seja, a presença do turismo massivo por um lado, e por outro, devido a existência de organização empresariais de grande porte. Nesse caso, os efeitos de encadeamento das atividades turísticas não extrapolam os limites do território de atuação do empreendimento, ficando restrito ao município.

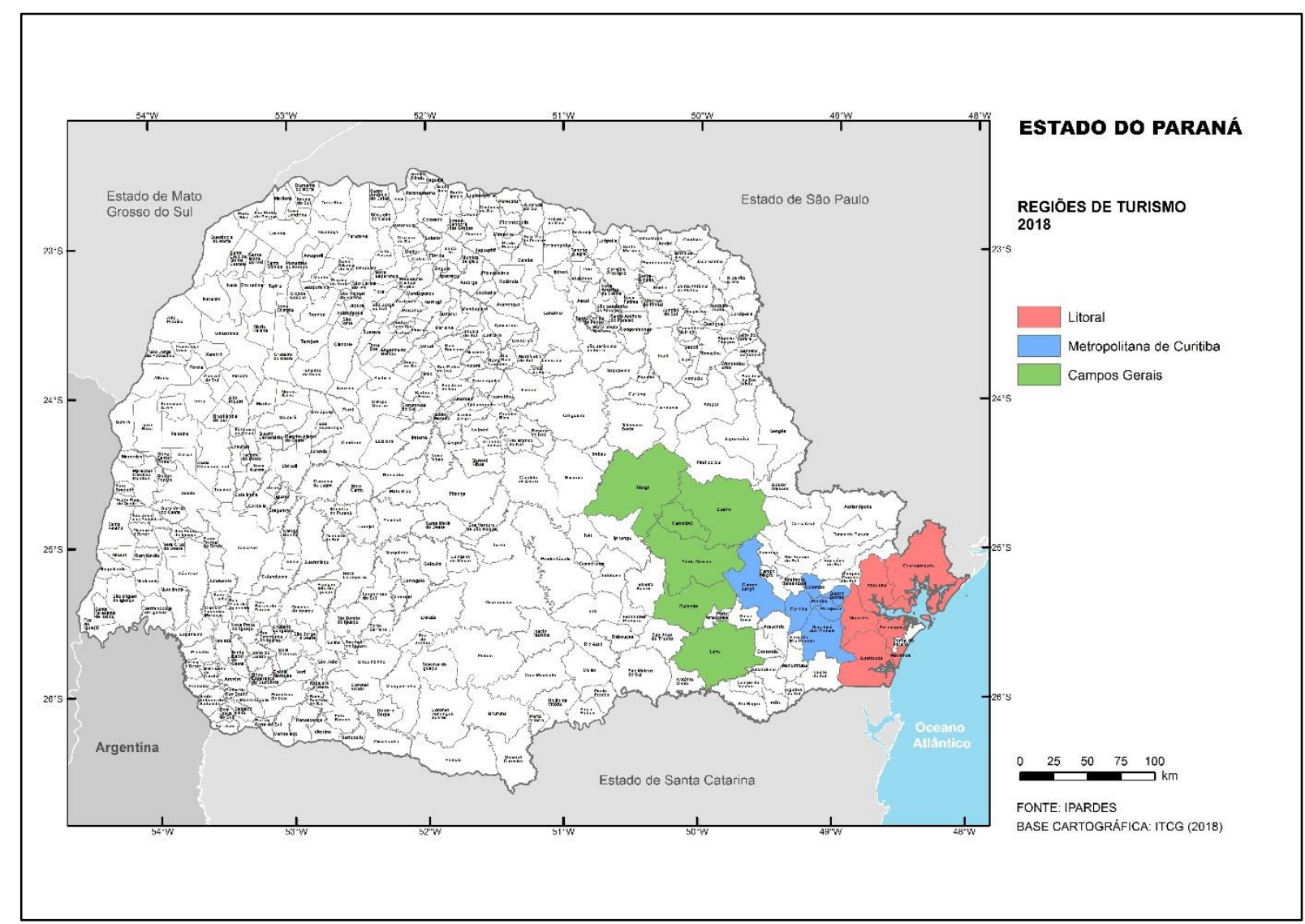

Figura 3. Regiões turísticas do Paraná em 2018

Fonte: Elaboração dos autores 
De fato, a proximidade dos grandes centros urbanos, que possuem concentração demográfica geradora de demanda, é primordial para o desenvolvimento da oferta de produtos turísticos oriundos dos municípios que compõe a região, principalmente, nas atividades relacionadas ao Enoturismo e a culinária local.

Essa condição é observada nos municípios de menor população localizados no entorno dos três polos regionais indicados na figura 3: Curitiba, Ponta Grossa e Paranaguá.

A Região Turística do Litoral é composta, segundo os critérios adotados neste trabalho, considerando as avaliações no TripAdvisor, pelos municípios de Guaraqueçaba, Paranaguá, Matinhos, Guaratuba, Antonina e Morretes. Os perfis dominantes nesse espaço geográfico são de buscadores de experiências de cultura, lazer e natureza devido à exuberante paisagem natural e ao valioso patrimônio arquitetônico e cultural que esses municípios oferecem. Contudo, cabe destaque à llha do Mel (pertencente administrativamente ao município de Paranaguá) e a Serra da Graciosa (em sua maior extensão localizada no município de Morretes).

A Região Turística Metropolitana de Curitiba é formada por Curitiba (já analisada ao longo deste estudo), São José dos Pinhais, Piraquara, Pinhais, Quatro Barras, Colombo e Campo Largo.

Com exceção de Curitiba, os demais municípios desta região disponibilizam maioritariamente atrativos turísticos para buscadores de experiências no Meio Rural, com destaque como oferta complementar para os souvenirs gastronômicos, que são produtos artesanais locais, em sua maioria elaborados a partir dos receituários dos antepassados dos proprietários, cuja tradição foi passada de geração para geração e que compõem os produtos geralmente a venda nessas propriedades.

A Região Turística dos Campos Gerais abrange Ponta Grossa, Lapa (apesar de pertencer à Região Metropolitana de Curitiba, turisticamente se enquadra nos Campos Gerais devido às suas características geográficas e 
culturais), Palmeira, Carambeí, Castro e Tibagi. Esse grupo tem como polo o município de Ponta Grossa e é caracterizado pela oferta de produtos para buscadores de experiências de evasão/cultura e natureza.

Cabe destacar os caminhos dos tropeiros, a composição étnica dos habitantes e os patrimônios históricos e culturais que esses municípios contemplam para a formação de roteiros turísticos. No caso da Lapa, município que se torna uma aposta no mercado nacional devido à sua riqueza histórica e patrimonial e pela proximidade da capital, destaca-se o Theatro São João, o Museu das Armas, Casa Cel. Joaquim Lacerda, o Museu Histórico da Lapa e o Pantheom dos Heróis.

Os municípios de Palmeira, Carambeí e Castro tem na sua formação étnica um importante componente na conformação dos atrativos turísticos ali estabelecidos. No caso de Palmeira é possível identificar a Colônia Witmarsum, situada a apenas $65 \mathrm{~km}$ de Curitiba e habitada por descendentes de imigrantes de origem alemã-russa conhecidos por Menonitas.

Seguindo a mesma lógica de Palmeira, o município de Castro se destaca pela Castrolanda, reduto holandês no estado, onde há um centro cultural e gastronomia típica da região, bem como Carambeí, com o seu Parque Histórico, o Festival de Tortas e seu vários Cafés.

Quanto a oferta de atrativos para buscadores de experiências de natureza, a região possui o atrativo Cânion Guartelá localizado no município de Tibagi.

Diante da breve apresentação dos principais atrativos turísticos do Estado do Paraná, na tentativa de conformação de destinos turísticos para o estado a partir da regionalização dos atrativos turísticos numa perspectiva de marketing, observa-se que há uma urgência de definições claras quanto a essa tipologia no sentido de orientar as políticas de marketing. 
Segundo Pearce (2016), "os destinos são um conjunto de produtos, serviços e experiências independentes oferecidos por múltiplos provedores privados e organizações públicas em determinados lugares com um ranking de escala que vai desde o local até o macro-regional" (p. 2). De fato, seguindo a definição de Pearce, foi possível agrupar destinos turísticos por meio de seu conjunto de atrativos e serviços turísticos de forma espacial e criando uma hierarquia que parte do local e vai até o macro-regional.

Antes disso, as tipificações de experiências são prementes à construção desse arcabouço espacial pois, conforme as classificações de Pine e Gilmore (1998), foi possível definir as ofertas dos atrativos de possíveis roteiros para os buscadores dos 10 perfis de experiências que abrangem o território paranaense.

Definidas as regiões, seguindo o referencial teórico proposto de acordo com as ideias de Buhalis (2000), Binkhorst (2008) e Neuhofer e outros (2012), a instrumentalização fica a cargo das Agências Gerenciadoras de Destinos, no passo que o impacto da tecnologia nas experiências é o novo paradigma no sentido de atrair turistas, com a inserção de diversos fatores que compõem a co-criação. Não por acaso, a região que melhor se adaptar a esse novo paradigma será a região com a maior probabilidade de desenvolvimento e consolidação de seus atrativos.

\section{CONCLUSÕES}

O turismo realizado de forma experiencial tem ganhado relevância devido à mudança do perfil dos viajantes contemporâneos, além da forte influência da Tecnologia de Informação e Comunicação amplamente estudados sob os auspícios das teorias do marketing de destinos turísticos e da economia de experiência.

No Paraná, diante dos esforços e comprometimento da governança formada pelo setor público, iniciativa privada, meios acadêmicos e sociedade civil seguindo os conceitos de DMO, amplamente discutido por Buhalis (2000) e Flores e Mendes (2014), foi possível analisar atrativos turísticos 
e criar uma ferramenta para compor roteiros de acordo com perfis de buscadores de experiências a partir das orientações dos Planos elaborados por meio da governança estabelecida.

Portanto, a partir deste estudo, será possível propor um aprofundamento das técnicas administrativas e políticas numa perspectiva interdisciplinar e integrada para o desenvolvimento turísticos das regiões identificadas. Tal perspectiva propõe o aprofundamento dos estudos do ordenamento territorial das regiões turísticas, com especial atenção ao papel das TICs no processo de desenvolvimento regional do Paraná.

De fato, tal assertiva foi levantada por Jovicic (2016), já exposta no marco teórico, quando levou em consideração o papel da Tecnologia da Comunicação e Informação na definição de destinos turísticos inteligentes e que é fundamental para o planejamento estratégico do marketing local num mundo cada vez mais globalizado e moderno.

Além dos fatores já apontados acima, as peculiaridades históricas, étnicas e demográficas na formação dos principais destinos permitiram a construção de um ambiente favorável à satisfação das necessidades dos turistas que buscam as experiências categorizadas segundo os critérios de Pine e Gilmore (1998). Contudo, os atrativos do estado ainda estão aquém de alcançar o desenvolvimento satisfatório do turismo experiencial aqui abordado.

Como resultado disso, identificou-se que as ofertas de destinos turísticos se caracterizam, na grande maioria dos casos, pela concentração territorial em torno dos grandes centros urbanos, pela homogeneidade dos territórios e dos atrativos turísticos, pela dinâmica demográfica dos municípios que as compõem. Tais condições são favorecidas pela existência de economias de escala e pelas externalidades positivas, como o fornecimento de infraestrutura de serviços e logística e pelo contingente demográfico, que gera a demanda por esses produtos. 
Tendo presente os resultados desta pesquisa, se considera que no Estado do Paraná a oferta de atrativos turísticos para buscadores de experiências, segundo uma perspectiva de marketing, ainda não está consolidada regionalmente, más apresenta potencial para tal.

De fato, a atuação da governança de gestão do destino turístico regional amparada na utilização das Tecnologias de Comunicação e Informação (TIC), como instrumento de gestão, determinará o sucesso da divulgação, implementação, monitoramento, avaliação e resultado do Planejamento Estratégico dos Destinos Turísticos.

Portanto, para fins de planejamento, é importante a utilização dos instrumentos da TIC associado ao uso dos conceitos de espaço turístico, ancorados nas ideias de Douglas Pearce (2016) e Barrado-Timon (2004) entre outros, para hierarquizar, propor e analisar os polos turísticos e conformar uma Regionalização do Turismo no território paranaense.

Contudo, o estudo identificou que é possível definir Regiões de Turismo no Estado desde uma perspectiva de marketing, o que certamente contribuirá para a conformação de produtos turísticos regionais competitivos.

\section{REFERÊNCIAS}

Amadeus (2015). Future Traveller Tribes 2030: undestending Tomorrow's Traveller.

Andersson, T.D. (2007). The tourist in the experience economy. Scadinavian Journal of Hospitality and tourism, $7(1): 46-58$

Ayikoru, M. (2009) Epistemology, ontology and tourism. In: TRIBE, j. Philosophical issues in toruism. UK/USA/Canada: Channel View: 62-79.

Barrado-Timon, D.A. (2004). El concepto de destino turístico. Una aproximación geográfico-territorial. Estúdios Turísticos, 160: 45-68

Binkhorst, E. (2008). Turismo de co-creación, valor añadido en escenarios turísticos. Journal of Tuourism Research - Revista de Investigacion en turismo, 1(1): 40-51 
Buhalis, D. (2000). Marketing the competitive destination of the future. ResearchGate, London, England: 1-27

Cohen, S.A., Prayag, G.\& Moital, M. (2016). Consumer behaviour in tourism: concepts, influences and opportunities. Current Issues in Tourism, 17(10): 872-909

Flores, L.C.S.\& Mendes, J.C (2014). Perspectivas do destino turístico: repensando o sentido do conceito. Revista Brasileira de Pesquisa em Turismo. São Paulo, 8(2): 222-237

Gray, D. E. (2012). Pesquisa no mundo real. Porto Alegre: Penso.

Grix, J. (2002). Introducing students to the generic terminology of social research. Political Studies Association, 22(3): 175-186.

Horodyski, G. S. (2014). O consumo na experiência turística: o caso dos souvenirs no destino Curitiba-PR. Tese (Doutorado) - Programa de Pós-Graduação em Geografia, Universidade Federal do Paraná, Curitiba

Jovicic, D.Z. (2016). Key issues in the conceptualization of tourism destinations. Tourism Geographies, 18(4): 445-457

Manosso, F.C. (2015). O espaço urbano turístico de Curitiba nas fotografias on-line: uma análise na rede social instagram. Dissertação (Mestrado) - Programa de Pós-Graduação em Geografia, Universidade Federal do Paraná, Curitiba

Mehmetoglu, M. \& Engen, M. (2015). Pine and Gilmore's concept of experience economy and its dimensions: An empirical examination in tourism. Journal of Quality Assurance in Hospitality e Tourism, 12(4): 237-255

Mondo, T.S. \& Gandara, J.M.G. (2017). O turismo experiencial a partir de uma perspectiva socioeconômica mercadológica. Revista de Análisis Turístico, 24: 26-40

Neuhofer,B., Buhalis, D. \& Ladkin,A (2012). Conceptualising technology enhanced destination experiences. Journal of Destination Marketing \& Management. 1: 36-46

Paraná Turismo (2016). Plano Paraná Turístico 2026 - Pacto para um destino inteligente, Curitiba Pearce, D. (2015). Toward an integrative conceptual framework of destinations. Journal of Travel Research, 53(2): 41-53.

Pearce, D. (2016). Modelos de gestión de destinos. Estudios y Perspectivas en Turismo, 25: 1-16.

Observatório de Turismo Paraná (2018). Plano Estratégico de Marketing Turístico 2018/2026, Curitiba Prebensen, N.K.; Foss, L. (2011). Coping and Co-creating in tourist experiences. International Journal of Tourism Research, 13: 54-67

Pine, B. \& Gilmore, J.H. (1998). Welcome to the experience economy. Harvard Business Reviw, julyAugust, 97-105. 
Richards, G. (2014). The new geographies of tourism: Space, place and locality. Paper presented at the Wageningen Geography Lectures: 1-20

Saraniemi, S.\& Kylanen, M. (2010). Problematizing the concept of tourism destination: An Analysis of different theoretical approaches. Journal of Travel Research, 50(2): 133-143

Thomaz, G. M.; Fecomércio-Pr; Paraná Turismo; Sebrae-PR; UFPR (2016). Personas/Perfis da demanda turística para o Paraná em 2026. Curitiba

TRIPAVISOR (2018). https://www.tripadvisor.com.br. Acesso entre fevereiro de março de 2018 